\title{
A REPRESENTAÇÃO SOCIAL DA HOMOFOBIA NA CIDADE DE LORENA/ SP
}

\author{
The social representation of \\ homophobia in the city of Lorena/SP
}

\section{Sonia Maria Ferreira Koehler}

D outora em Psicologia Escolar e do D esenvolvimento Humano, Coordenadora do Observatório de Violências na Escola do Centro Universitário Salesiano de São Paulo, Unidade de Lorena, SP - Brasil, e-mail: koehler@guaranet.com.br

\section{Resumo}

Este trabalho é produto de uma pesquisa em andamento realizada pelo Observatório de Violências nas Escolas, do Núcleo UNISAL, Lorena/ SP, que estuda conflitos, clima escolar, exclusão, preconceitos, direitos humanos, convívio, tolerância e respeito pelo "Ser" humano no ambiente escolar. 0 objetivo foi investigar a representação social em relação ao fenômeno da homofobia da comunidade de Lorena/ SP, representados por adolescentes, adultos e idosos, com idade entre 16 e 84 anos, que transitavam pela praça principal da cidade de Lorena. Foram realizadas 671 entrevistas, 330 no ano de 2006 e 341 em 2007. Caracterizada como um survey longitudinal, pois uma determinada população foi estudada em ocasiões diferentes e representada por diferentes indivíduos o que permite a análise do processo de mudança

Rev. Diálogo Educ., Curitiba, v. 9, n. 28, p. 587-604, set./ dez. 2009 
no tempo. $\mathrm{O}$ instrumento de pesquisa utilizado foi uma entrevista do tipo semiestruturado com questões abertas e fechadas. Os dados das questões abertas estão submetidos à metodologia segundo os princípios da análise de conteúdo. Compreender o pensamento e a opinião das pessoas sobre a homofobia é fundamental para se pensar formas de esclarecer e instrumentalizar os educadores ao lidar com a temática em questão. A partir da categorização dos dados e da análise das respostas obtidas, almeja-se ações ao nível de prevenção primária e secundária que contribuam com as políticas públicas, assim como na redução do sentimento homofóbico, do preconceito e da discriminação relacionada à homossexualidade, consequentemente contribuir com a promoção dos direitos humanos.

Palavras-chave: Representação social. Homofobia. Homossexualidade. Gênero. Educação sexual.

\begin{abstract}
This essay results from a research in progress that has been carried out by the Observatory of School Violence, headed by a research group of UNISAL, located in Lorena/SP, which studies conflicts, school climate, exclusion, prejudices, Human Rights, learn to live with, Tolerance, and respect for "Being" human in school environment. The aim was to investigate, on a community located in Lorena, the social representation in relation to the homophobia phenomenon performed by adolescents, adults and elderly, aged 16 to 84, who have wandered the main city square. There was carried out 671 interviews, 330 in 2006 and 341 in 2007. Established as a longitudinal survey, since it has studied a given population in distinct occasions represented by different individuals, it allows for an analysis of the shifting process through the time. The research tool used was a semi-structured interview composed by open and close questions. The data taken from the open questions has been submitted to a methodology in conformity with tenets of content analysis. The grasp of thoughts and judgements about homophobia is basic to try new ways of clarification, as such giving educators the necessary tools to cope with the subject in discussion. By
\end{abstract}

Rev. Diálogo Educ., Curitiba, v. 9, n. 28, p. 587-604, set./ dez. 2009 
means of data categorization and from the analysis of the obtained responses, it means to bring about actions towards primary and secondary level prevention to contribute to public politics, as well as to the reduction of homophobic feelings, prejudice and discrimination against homossexuality, and, subsequently, to help to promote human rights.

Keywords: Social representation. Homophobia. Homossexuality. Gender. Sex education.

\section{INTRODUÇÃO}

Esta pesquisa sobre "a representação social da homofobia" faz parte de um conjunto de projetos que estão se delineando a partir de um grupo de professores e alunos do Centro UNISAL ${ }^{1}$ de Lorena, pertencentes ao grupo de estudos do O bservatório de Violências nas Escolas, cujo objetivo é pesquisar, desenvolver projetos-ação e propor intervenção nas escolas. Está direcionado, portanto, a pesquisadores, gestores públicos, educadores, pais, alunos e todas as pessoas que tenham preocupações com as violências nas escolas e com a construção de uma cultura de paz. ${ }^{2}$

Nossa história carrega traços deviolência física, étnica, cultural, política, religiosa, ideológica, psicológica, enfim, ontológica. Basta olharmos para a situação dos índios, para o racismo em relação aos negros, para o preconceito social. Muitas dessas formas de violência circulam nosso cotidiano mostrando claramente o quanto ainda estamos presos a uma cultura abusiva, autoritária e desumana, que coisifica, petrifica, despersonaliza e torna o ser humano vulnerável a tudo o que diz respeito à dimensão do "Ser" (K O E HLER, 2003). Uma das questões sociais atuais aponta para a necessidade de estudos sobre 0 comportamento/sentimento homofóbico, pois ao considerar, objetivamente, como uma das principais funções da E scola na atualidade,

UNISAL - Centro Universitário salesiano de São Paulo. Está sediado em Americana com outros câmpus na cidade de São Paulo, Campinas e Lorena.

2 Observatório de Violências na Escola é uma parceria entre o UNISAL, Universidade Católica de Brasília, UCB e Unesco. Em 13 de maio de 2008, a Unesco aprovou a Cátedra de Juventude, Educação e Sociedade da Universidade Católica de Brasília, qual o UNISAL mantém-se como parceiro.

Rev. Diálogo Educ., Curitiba, v. 9, n. 28, p. 587-604, set./ dez. 2009 
a socialização e a humanização, deve, portanto, possibilitar a compreensão dos diferentes tipos de relações sociais.

0 assunto homofobiaapresenta-se como um complexo assunto para os pesquisadores que estudam as violências na escola, pois envolve inclusão/ exclusão, educação para a sexualidade, orientação sexual, identidade sexual, estudos sobre gênero e homossexualidade. 0 desafio é enorme. Há um silêncio velado dentro da própria universidade, o que demonstra a diversidade de opiniões, conceitos e crenças tanto no discurso acadêmico quanto no senso comum.

A pesquisa de A bramovay, Castro e Silva (2004) com estudantes, pais e professores em 13 capitais brasileiras e no Distrito Federal, proporcionam dados a partir de observação in loco, questionários (24.053 respondentes), entrevistas individuais (577) e grupos focais (1.730 participantes) cujo tema foi a sexualidade juvenil. A pesquisa demonstra que muitos jovens são alvo de violências como assédio, estupro e discriminação de gênero ou por orientação sexual, atingindo 10\% em algumas das capitais pesquisadas. $0 \mathrm{~s}$ dados apontam para a necessidade de pesquisas que abordem as relações de gênero e violência escolar.

A intersecção da violência com as relações de gênero funda-se no processo da cultura enquanto meio formador de crianças e jovens a partir da construção social de um conjunto de representações, valores, atributos que caracterizam o masculino e o feminino (VIANNA; RIDENTI, 1998).

G ênero é entendido como uma construção social, um conceito contemporâneo e sociológico, que questiona o determinismo biológico e as diferenças entre os papéis de homem e mulher. 0 s elementos desses papéis incluem vestimentas, modo de falar, gestos, profissão e outros fatores que não são limitados pelo sexo biológico. Esses elementos incorrem na importância de compreender o termo "Identidade sexual" ou pode ser entendido como um sentimento de masculinidade ou feminilidade que acompanhaa pessoa ao longo da vida. São preferências, sentimentos e atitudes que nem sempre estão de acordo com o sexo biológico (masculino/ feminino). A identidade sexual determina o que chamamos de "O rientação sexual", que vem a ser a atração afetiva e/ ou sexual que uma pessoa tem pela outra. Continuum que varia da homossexualidade exclusiva a heterossexualidade exclusiva e diversas formas de bissexualidade. Podemos escolher demonstrar ou não nossos sentimentos. (FO UCAULT, 1999; GID DENS, 1993).

A orientação sexual e a identidade de gênero são categorias reconhecidas pelo Ministério da Saúde como determinantes e

Rev. Diálogo Educ., Curitiba, v. 9, n. 28, p. 587-604, set./ dez. 2009 
condicionantes da situação de saúde, não apenas por implicarem práticas sexuais e sociais específicas, mas também por expor lésbicas, gays, bissexuais, travestis e transexuais a agravos decorrentes do estigma e da exclusão social. 0 que é homossexualidade?

A homossexualidade é a atração afetiva e sexual por uma pessoa do mesmo sexo. São aqueles indivíduos que têm orientação sexual e afetiva por pessoas do mesmo sexo. D a mesma forma que a heterossexualidade (atração por uma pessoa do sexo oposto) não tem explicação, a homossexualidade também não tem. D epende da orientação sexual de cada pessoa (FOUCAULT, 1999; MOTT, 2006).

A homossexualidade foi retirada da relação de doenças pelo Conselho Federal de Medicina em 1985, e o Conselho Federal de Psicologia determinou, em 1999, que nenhum profissional pode exercer "a ação que favorece a patologização de comportamentos ou práticas homoeróticas" (BRASIL, 2004).

A literatura nos mostra as diferentes formas de exercer a sexualidade e busca esclarecer os conceitos que denotam a "orientação sexual das pessoas" (MO TT, 2006):

- Gays: são indivíduos que, além de se relacionarem afetiva e sexualmente com pessoas do mesmo sexo, têm um estilo de vida de acordo com essa sua preferência, vivendo abertamente sua sexualidade;

- Bissexuais: são indivíduos que se relacionam sexual e/ ou afetivamente com qualquer dos sexos. Alguns assumem as facetas de sua sexualidade abertamente, enquanto outros vivem sua conduta sexual de forma fechada;

- Lésbicas: terminologia utilizada para designar a homossexualidade feminina.

- Transgêneros: terminologia utilizada que engloba tanto os travestis quanto os transexuais. É um homem no sentido fisiológico, mas se relaciona com o mundo como mulher;

- Transexuais: são pessoas que não aceitam o sexo que ostentam anatomicamente. Sendo o fator psicológico predominante na transexualidade, 0 indivíduo identifica-se com o sexo oposto, embora dotado de genitália externa e interna de um único sexo.

A "externalização" dos diferentes comportamentos que demonstram "orientação sexual" diferente da heterossexual tem causado

Rev. Diálogo Educ., Curitiba, v. 9, n. 28, p. 587-604, set./ dez. 2009 
diferentes formas de pensar e agir nos mais diversos segmentos da população, assim como, entre os profissionais da educação e no interior da escola, portanto compreender o pensamento e a opinião das pessoas sobre 0 assunto é uma etapa importante para buscarmos formas de esclarecer e instrumentalizar os profissionais para "lidar" com 0 assunto. O que é "Homofobia?". Segundo Smigay (2002, p. 34):

Homofobia ainda é um conceito ambíguo, geralmente associado a homossexualidade, uma postura de rejeição, de medo de contato [...] Se tomamos sua etimologia, a palavra homo, seja em grego ou latim, quer dizer o mesmo, 0 idêntico, mas também homem;e fobia o medo - nesse caso, o medo de outros homens.

No relatório da Unesco, o termo homofobia refere-se ao tratamento preconceituoso e às discriminações sofridas por jovens tidos como homossexuais, sendo inúmeras as formas de desvalia das sexualidades ditas não-hegemônicas, ferindo a dignidade alheia e gerando sofrimentos e revoltas (ABRAMOVAY; CASTRO; SILVA, 2004). Nesse sentido, comportamentos homofóbicos variam desde a violência física da agressão e do assassinato até a violência simbólica e/ ou psicológica (KO EHLER, 2003), em que alguém considera lícito afirmar que não gostaria de ter um colega ou um aluno homossexual.

No grupo de estudos e pesquisas do O bservatório de Violências nas Escolas do UNISAL/ Lorena, em 2007, uma diretora de escola municipal envolvida, comprometida com o pedagógico, com a inclusão, relatou ao grupo o seguinteacontecimento: dois rapazes haviam procurado a escola para matrícula no período noturno. Como o período letivo já havia começado, ela recebeu os dois em sua sala. Quando os rapazes sentaram e começaram a conversar, ela percebeu tratar-se de um casal gay, que assumia naturalmente estarem casados. Enquanto eles explicavam 0 motivo do atraso para a matrícula e comentavam sobre o trabalho que faziam e a necessidade de continuarem estudando, a diretora olhava para eles e pensava: "nossa, o que vou fazer? E sea turma da sala não aceitá-los? Q ual banheiro eles vão usar? E se comecarem a zombar deles?"....

No grupo de estudos ela estava indignada com sua própria paralisação diante do acontecido, pois afirmava não ter preconceito e que por estar estudando o assunto, deveria ter tido uma reação natural com 0 pedido dos rapazes. Porém o fato se tornara um problema, e ela estava angustiada diante de todos os sentimentos e pensamentos a respeito da homossexualidade, pois em mais de 15 anos de magistério nunca havia

Rev. Diálogo Educ., Curitiba, v. 9, n. 28, p. 587-604, set./ dez. 2009 
estado envolvida em uma circunstância com um casal gay que, face a face, pedia-lhe orientação sobre estudos e vagas em sua escola.

O relatório Brasil Sem Homofobia (BRASIL, 2004) é sem dúvida a melhor exposição do fenômeno em nossa sociedade contemporânea. Ele cita alguns exemplos pontuais decorrentes da ausência da reflexão sobre gênero e sexualidade nas escolas, entre os quais destaca-se um estudo de Ramires N eto (2006), que analisa um caso muito interessante da desatenção às questões de gênero: 0 fato de uma professora brincar com um aluno perguntando se o nome dele é Fabiano ou Fabiana. $\mathrm{O}$ episódio gerou chacotas e brincadeiras para 0 aluno durante todo 0 ano letivo, e isso dá a dimensão da capacidade de interferência do educador nas relações escolares etambém daimportância de cursos como estes. O exemplo é importante para pensarmos no quanto a linguagem está implicada na constituição dos sujeitos, no poder que certas coisas adquirem ao serem ditas e como essas falas e esses discursos subjetivam. 0 referido fato nos obriga a refletir sobre como a escola pode produzir vulnerabilidades através da linguagem.

0 relatório mostra que a escola é uma instância de disciplinamento da sexualidade (heterossexual), configurando-se em um território no qual se constituem e se reproduzem mecanismos homofóbicos. Isso nos remete a questão do heterossexismo enquanto institucionalização da norma ou padrão heterossexual, que estabelece e perpetua a no ção de que to das as pessoas são ou devem ser heterossexuais, excluindo as necessidades, as preocupações, as culturas e as experiências de vida dos gays, lésbicas, bissexuais e transgêneros. Conforme Junqueira (2007, p. 61), a escola é um lugar em que jovens GLBT enfrentam, sistematicamente, discriminações por parte de colegas, professores, dirigentes e servidores escolares e "não raro encontram obstáculos para se matricularem na rede pública, participarem de atividades pedagógicas e terem suas identidades minimamente respeitadas".

\section{A pesquisa - o panorama teórico}

A pesquisa se caracteriza como um survey longitudinal, pois, segundo Babbie (1999), uma determinada população estudada em ocasiões diferentes e representada por diferentes indivíduos permite a análise do processo de mudança no tempo.

A creditamos que a primeira contribuição para a compreensão do fenômeno é ouvir indivíduos ou grupos sobre o que pensam/ entendem sobre homofobia. Para tanto, escolhemos 0 referencial

Rev. Diálogo Educ., Curitiba, v. 9, n. 28, p. 587-604, set./ dez. 2009 
teórico das representações sociais de Moscovici (1978), ao considerar que as representações sociais são uma forma de conhecimento que envolve um universo de opiniões, atitudes, crenças, informações socialmente elaboradas e partilhadas, valores coletivos que se modificam e que concorrem para a construção de uma realidade comum a um conjunto social. universo de opiniões, por sua vez, possui várias dimensões: a informação, o campo de representação e a atitude. A informação delineia a quantidade e a organização dos conhecimentos em um universo de opinião (de um grupo ou de uma classe social) a cerca de um dado objeto social qualquer como, por exemplo, do racismo, da homossexualidade, de uma do ença contagiosa, etc. Jodelet (1991) aponta que, em se tratando de representações sociais, as definiçõ es partilhadas pelos membros de um mesmo grupo constroem visões consensuais sobre determinados assuntos, o que orienta e organiza as condutas e comunicações sociais. Portanto, por esta abordagem, é possível analisar o pensamento e a prática social de um determinado grupo.

\section{METODOLOGIA}

Participantes: 0 s participantes deste estudo foram transeuntes da praça principal da Cidade de Lorena, SP que transitavam no horário das atividades em comemoração ao Dia do Psicólogo denominadas "Psicologia na Praça". Foram convidados a participarem por adesão espontânea após explicação dos objetivos da pesquisa. A coleta dos dados aconteceu em dois anos consecutivos: 2006 com 330 participantes, 2007 com 341 participantes, totalizando 671. D istribuídos nas seguintes faixas etárias - 2006 - 22,12\% entre 16 a 20 anos, 31,52\% entre 21 a 30 anos, $13,64 \%$ entre 31 a 40 anos, $15,45 \%$ entre 41 a 50 anos, $8,48 \%$ entre 51 a 60 anos e 8,79\% acima de 61 anos. 2007 - 23,46\% entre 16 a 20 anos, $35,19 \%$ entre 21 a 30 anos, 13,49\% entre 31 a 40 anos, 13,49\% entre 41 a 50 anos, 8,21\% entre 51 a 60 anos e 6,16\% acima de 61 anos.

E m 27 deagosto de 2008, foi (re)aplicado o mesmo instrumento de pesquisa nas mesmas condições explicitadas acima. A partir do tratamento dos dados, serão feitos a análise detalhada e o cruzamento das informações dos anos 2006, 2007 e 2008 considerando o sexo, idade, escolaridade, religião, o que pensam e imaginam os participantes sobre homofobia e homossexualidade.

Rev. Diálogo Educ., Curitiba, v. 9, n. 28, p. 587-604, set./ dez. 2009 
Procedimentos: Alunos do $4^{\circ}$ semestre do Curso de Psicologia do Centro UNISAL de Lorena foram devidamente treinados e orientados quanto à aplicação do questionário e às questões éticas envolvidas em uma pesquisa. Os questionários foram aplicados por esses alunos nos dias 27/08/2006 e 27/08/2007, durante as comemorações do Dia do Psicólogo, realizadas na praça central da cidade de Lorena-SP quando a população é convidada a participar de atividades diversas realizadas ao longo do dia. O s alunos convidaram os transeuntes, na faixa etária acima dos 16 anos, a responderem às questões, individualmente e por adesão espontânea.

Instrumento: foi utilizado um questionário semiestruturado dividido em duas partes. A primeira foi usada para a identificação do participante: sexo, idade, religião, profissão, etnia, escolaridade. Para este trabalho foram selecionadas duas questões da segunda parte:

1) $O$ que você imagina que seja homofobia?

2) $\mathrm{O}$ que você imagina que seja homossexualidade?

As respostas dos participantes foram analisadas através da análise de conteúdo temática, segundo os princípios de Bardin (1977). A organização dos dados foi realizada por meio da sistematização de respostas dos participantes, identificando e classificando as categorias mais significativas. As categorias de análise foram estruturadas a partir das expressões verbais e segundo os padrões de repetição. O s resultados foram distribuídos em tabelas pelo ano de aplicação, faixas de idade e as questões propostas.

O s estudos preliminares demonstram o conhecimento da população pesquisada sobre os conceitos de homofobia e homossexualidade. A proposta de continuidade da pesquisa é analisar os significados associados a homofobia e homossexualidade entre homens e mulheres; identificar relações entre os significados, gênero, faixa etária, religião e grau de instrução; analisar as possíveis mudanças ocorridas nas "representações sociais" sobre a compreensão do conceito; propor e elaborar um projeto de intervenção "primária" para a Rede Escolar; e contribuir com dados para as políticas públicas.

A Tabela 1 mostra as categorias sobre o significado do termo homofobia para os participantes desta pesquisa.

Rev. Diálogo Educ., Curitiba, v. 9, n. 28, p. 587-604, set./ dez. 2009 
KOEHLER, S. M. F.

TABELA 1 - 0 que você imagina que seja homofobia?

\begin{tabular}{|c|c|c|c|c|c|c|c|c|c|c|c|c|c|c|}
\hline \multirow{2}{*}{$\begin{array}{l}\text { Faixa etána } \\
\text { Categonias }\end{array}$} & \multicolumn{2}{|c|}{$16-20$} & \multicolumn{2}{|c|}{$21-30$} & \multicolumn{2}{|c|}{$31-40$} & \multicolumn{2}{|c|}{$41-50$} & \multicolumn{2}{|c|}{$51-60$} & \multicolumn{2}{|c|}{61 ou mais } & \multicolumn{2}{|c|}{$\begin{array}{c}\text { Total } \\
\text { comparativo }\end{array}$} \\
\hline & 2006 & 2007 & 2006 & 2007 & 2006 & 2007 & 2006 & 2007 & 2006 & 2007 & 2006 & 2007 & 2006 & 2007 \\
\hline $\begin{array}{l}\text { Doença } \\
\text { (biológico) }\end{array}$ & 12 & 5 & 6 & 10 & 3 & 3 & 2 & 4 & 1 & 1 & 7 & 4 & 31 & 27 \\
\hline $\begin{array}{l}\text { Homos- } \\
\text { sexualidade }\end{array}$ & 3 & 4 & 1 & 9 & 1 & 2 & 1 & 3 & 1 & 0 & 0 & 1 & 7 & 19 \\
\hline $\begin{array}{l}\text { Interpret } \\
\text { ou Homos- } \\
\text { sexualidade } \\
\text { e/ ou homem } \\
\text { + Fobia } \\
\text { (medo) }\end{array}$ & 0 & 10 & 16 & 18 & 6 & 7 & 4 & 6 & 2 & 2 & 3 & 2 & 31 & 45 \\
\hline $\begin{array}{l}\text { Não sabe } \\
\text { S/ R }\end{array}$ & 21 & 17 & 21 & 25 & 18 & 7 & 17 & 5 & 2 & 10 & 4 & 5 & 83 & 69 \\
\hline $\begin{array}{l}\text { Medo/ } \\
\text { pavor (por } \\
\text { alguma coisa) }\end{array}$ & 27 & 21 & 37 & 38 & 12 & 15 & 20 & 24 & 15 & 13 & 4 & 5 & 115 & 116 \\
\hline $\begin{array}{l}\text { Conceito } \\
\text { correto } \\
\text { (aproximado) }\end{array}$ & 5 & 11 & 11 & 10 & 3 & 5 & 2 & 1 & 0 & 0 & 0 & 0 & 21 & 27 \\
\hline Outros & 1 & 3 & 9 & 3 & 5 & 1 & 5 & 4 & 7 & 2 & 3 & 1 & 30 & 14 \\
\hline
\end{tabular}

Fonte: Campo de pesquisa, organizado pela autora.

Rev. Diálogo Educ., Curitiba, v. 9, n. 28, p. 587-604, set./ dez. 2009 
Abaixo apresentamos as emissões dos participantes agrupadas conforme os significados agrupados por categorias. 0 que vocêimagina que seja homofobia?

Doença (biológico) - "síndrome", "doença compulsiva de alimentação, acho que é uma doença", "doença ligada ao sistema nervos", "depressa", "distúrbio ou tendência", "problema de respiração";

Homossex ualidade - "casal gay", "o mesmo que homossexualidade", "homem que gosta de homem", "homem que tem relação com outro homem, pessoas que gostam de pessoas do mesmo sexo", "pessoas que tem um afeto com pessoas do mesmo sexo", "pessoas que se atraem pelo mesmo sexo";

Interpretou H omossexualidadee/ ou homem + Fobia (medo) - "fobia de homem", "pânico de homem", "medo de homem, medo de homossexual", "medo ou repulsão ao mesmo sexo";

Não sabe e S/ R - "Não Imagina", "não tem ideia", "não sei", "nunca ouvi falar";

Medo/ pavor/ pânico (por alguma coisa) - "ficar preso no elevador"," de lugar fechado", "de pessoas", "da sociedade", "multidão", "aranha", "falta de ar", "de altura", "medo de alguma coisa igual", "medo de algo";

Conceito correto (aproximado) - "fobia a homossexuais", "aversão a homossexuais", "rejeição/ preconceito contra homossexuais", "pessoa que tem raiva de homossexual";

Outros - "pedofilia", "homem louco", "sabão em pó", "preconceitos com raça diferente", "troca de humor", "pessoa que esquece das coisas", "preconceito com o sexo oposto".

Rev. Diálogo Educ., Curitiba, v. 9, n. 28, p. 587-604, set./ dez. 2009 
KOEHLER, S. M. F.

A Tabela 2 mostra as categorias do significado do termo homossexualidade para os participantes da pesquisa.

TABELA 2 - 0 que você imagina que seja homofobia?

\begin{tabular}{|c|c|c|c|c|c|c|c|c|c|c|c|c|c|c|}
\hline \multirow{2}{*}{$\begin{array}{l}\text { Faixa etánia } \\
\text { Categonias }\end{array}$} & \multicolumn{2}{|c|}{$16-20$} & \multicolumn{2}{|c|}{$21-30$} & \multicolumn{2}{|c|}{$31-40$} & \multicolumn{2}{|c|}{$41-50$} & \multicolumn{2}{|c|}{$51-60$} & \multicolumn{2}{|c|}{61 ou mais } & \multicolumn{2}{|c|}{$\begin{array}{c}\text { Total } \\
\text { comparativo }\end{array}$} \\
\hline & 2006 & 2007 & 2006 & 2007 & 2006 & 2007 & 2006 & 2007 & 2006 & 2007 & 2006 & 2007 & 2006 & 2007 \\
\hline $\begin{array}{l}\text { Nomes } \\
\text { pejorativos }\end{array}$ & 3 & 6 & 2 & 5 & 0 & 2 & 1 & 0 & 3 & 1 & 4 & 2 & 13 & 0 \\
\hline $\begin{array}{l}\text { D oença } \\
\text { (genética) }\end{array}$ & 0 & 1 & 1 & 1 & 3 & 3 & 3 & 1 & 2 & 3 & 3 & 3 & 12 & 12 \\
\hline $\begin{array}{l}\text { Opinião } \\
\text { de valor } \\
\text { (certo / } \\
\text { errado) }\end{array}$ & 14 & 9 & 9 & 12 & 7 & 4 & 3 & 1 & 1 & 3 & 6 & 1 & 40 & 30 \\
\hline $\begin{array}{l}\text { Desvio de } \\
\text { compor- } \\
\text { tamento / } \\
\text { Psicológico }\end{array}$ & 3 & 1 & 8 & 5 & 0 & 1 & 4 & 4 & 2 & 2 & 2 & 0 & 19 & 13 \\
\hline $\begin{array}{l}\text { Homosse- } \\
\text { xualismo } \\
\text { Masculino }\end{array}$ & 12 & 9 & 12 & 22 & 7 & 6 & 12 & 12 & 5 & 6 & 4 & 6 & 52 & 61 \\
\hline $\begin{array}{l}\text { Homosse- } \\
\text { xualismo }\end{array}$ & 26 & 41 & 52 & 57 & 19 & 20 & 14 & 15 & 7 & 5 & 4 & 3 & 122 & 141 \\
\hline Bissexual & 0 & 2 & 2 & 1 & 3 & 1 & 2 & 7 & 0 & 0 & 0 & 0 & 7 & 11 \\
\hline Heterossexual & 2 & 0 & 1 & 0 & 0 & 0 & 1 & 0 & 0 & 0 & 1 & 0 & 5 & 0 \\
\hline Travesti & 2 & 2 & 3 & 3 & 1 & 4 & 3 & 2 & 2 & 4 & 2 & 1 & 13 & 16 \\
\hline Transexual & 1 & 0 & 0 & 0 & 0 & 0 & 0 & 0 & 0 & 0 & 1 & 0 & 2 & 0 \\
\hline $\begin{array}{l}\text { Não sabe / } \\
\text { Não imagina/ } \\
\text { S/ R }\end{array}$ & 8 & 1 & 7 & 0 & 6 & 0 & 8 & 0 & 4 & 2 & 3 & 0 & 36 & 3 \\
\hline Outros & 2 & 5 & 3 & 7 & 0 & 5 & 3 & 5 & 3 & 2 & 2 & 2 & 13 & 26 \\
\hline
\end{tabular}

Fonte: Campo de pesquisa, organizado pela autora.

Rev. Diálogo Educ., Curitiba, v. 9, n. 28, p. 587-604, set./ dez. 2009 
A representação social da homofobia na cidade de Lorena/ SP 599

D escrevemos abaixo as emissões dos participantes agrupadas conforme os significados agrupados por categorias. O quevocê imagina que seja homossexualidade?

Nomes pejorativos - "coisa de viado", "corta para os dois lados", "meio bicha", "bicha", "uma pessoa que não tem o que fazer", "pessoa desmunhecada";

D oença - genética - "problemafísico, hormonal", "aberração da natureza", "doença", "nasceu assim", "erro da natureza", "genética", "vem de nascença", "hereditário",

O pinião de valor - "eu não sou a favor nem contra", "eu não acho certo não", "nada contra", "não tenho preconceito", "é uma opção", "eu sou machista, acho errado"; é uma provação", "educação", "falta vergonha na cara", "D eus não aceita", "não está nos planos de D eus", "novo sexo";

Desvio de Comportamento (psicológico) - "distúrbio", "desvio de personalidade", "desiquilíbrio psicológico e emocional", "fraqueza";

Homossexual masculino - "homem com homem", "homem que gosta de homem", "relação de homens", "o cara gostar de outro cara", "são gays", "quando homens do mesmo sexo ficam juntos", "homem que sai com homem";

Homossexual - (definição) "relacionamento afetivo/ sexual entre pessoas do mesmo sexo" - "pessoado mesmo sexo quenamoram", pessoas que se relacionam com outras do mesmo sexo", "pessoas que gostam de pessoas do mesmo sexo", "envolvimento de duas pessoas do mesmo sexo", "pessoa que tem atração sexual por pessoas do mesmo sexo", "atração por pessoas do se próprio sexo", "preferênciaporum parceiro do seu mesmo sexo", "pessoas do mesmo sexo que se amam e se gostam',

Bissexual - "quem fica com homem e mulher", "interesse por pessoas dos dois sexos", "homem que gosta de homem e de mulher", "tem vida dupla, com homem e com mulher", "tanto faz ficar com homem como com mulher";

Heterossexual - "relação com sexo diferente", "gostar de pessoa do sexo oposto;

Travesti - "travesti", "homem que ganha a vida se vestindo de mulher", "homem que se veste de mulher";

Transexual - "homem/ mulher que é uma coisa e quer ser outra", "homem que quer virar mulher";

Rev. Diálogo Educ., Curitiba, v. 9, n. 28, p. 587-604, set./ dez. 2009 
Não sabe - "não sei", "não sei explicar", "sei o que é, mas não sei definir";

O utros - "dois sexos", "diversidade de sexo", "relação entre casais", "é uma palavra que tem um sexo, mas acha que tem outro", "um transando com o outro", "o mesmo que homofobia", "existem dois tipos: aquele que é interessado e aquele que não é".

Chama-nos a atenção o fato de que o termo "lésbica", ou a referência so bre a homossexualidade feminina não apareceu para que se configurasse em categoria. A homossexualidade feminina aparece na categoria "homossexual" enquanto definição geral, por ex: "pessoa que gosta e/ ou tem atração por pessoa do mesmo sex o".

\section{CONSIDERAÇÕES FINAIS}

D iante dos dados coletados sobre a percepção de adolescentes, adultos e idosos da cidade de Lorena - SP sobre o que imaginam que seja homofobia e homossexualidade, fica mais próxima a possibilidade de estudos, reflexões e discussões que viabilizem novas propostas de intervenções que minimizem este tipo de Violências nas Escolas.

O Programa Brasil Sem Homofobia (BRASIL, 2004), cujo relatório propõe onze programas de combateà violência eà discriminação contraG LTB epromoção dacidadaniahomossexual, precisa ser difundido, estudado e discutido entre os educadores. Cada programa é desmembrado em diferentes segmentos que apontam as ações que, sem dúvida, devem ser articuladas por pesquisadores e universidades comprometidas com 0 desenvolvimento humano, a expansão da consciência, 0 combate à discriminação. Abaixo estão relacionadas algumas ações do "Relatório Brasil Sem Homofobia" as quais podemos e devemos nos dedicar:

- criar estudos e pesquisas sobre a discriminação múltipla ocasionada pelo racismo, homofobia e preconceito de gênero;

- criar instrumentos técnicos para diagnosticar e avaliar as múltiplas formas de discriminação combinadas com 0 racismo, homofobia e preconceito de gênero;

- articular e desenvolver, em parceria com outras áreas governamentais, ações de publicidade e de utilidade pública, campanhas institucionais para a divulgação do Programa de

Rev. Diálogo Educ., Curitiba, v. 9, n. 28, p. 587-604, set./ dez. 2009 
A representação social da homofobia na cidade de Lorena/ SP 601

Combate à Violência e à D iscriminação contra G LTB e de Promoção da Cidadania Homossexual, Brasil Sem Homofobia, visando a ampliar o repasse de informações sobre o tema e, sobretudo, sensibilizar a sociedade brasileira para uma cultura de paz e de não-violência e nãodiscriminação contra homossexuais;

- apoiaraimplementação deprojetosdeprevenção dadiscriminação e da homofobia nas escolas, em parceria com agências internacionais de cooperação e com a sociedade civil organizada;

- capacitar profissionais de casas de apoio e de abrigos para jovens em assuntos ligados à orientação sexual e ao combate à discriminação e à violência contra homossexuais, em parceria com agências internacionais de cooperação e a sociedade civil organizada.

No que diz respeito diretamente à educação, que envolve a promoção de valores, de respeito à paz e não-discriminação por orientação sexual, há um longo trabalho a ser feito:

- elaborar diretrizes que orientem os Sistemas de Ensino na implementação de ações que comprovem o respeito ao cidadão e à não-discriminação por orientação sexual;

- fomentar e apoiar curso de formação inicial e continuada de professores na área da sexualidade;

- formar equipes multidisciplinares para avaliação dos livros didáticos, de modo a eliminar aspectos discriminatórios por orientação sexual e a superação da homofobia;

- estimular a produção de materiais educativos (filmes, vídeos e publicações) sobre orientação sexual e superação da homofobia;

- apoiar e divulgar a produção de materiais específicos para a formação de professores;

- divulgar as informações e estimular a pesquisa e a difusão de conhecimentos que contribuam para o combate à violência e à discriminação de GLTB.

Nesse sentido, a universidade não pode silenciar. Compreender o pensamento e a opinião das pessoas sobre a homofobia é fundamental para se planejar formas de esclarecer e instrumentalizar os educadores para lidar com a questão. O enfrentamento de todos os tipos de

Rev. Diálogo Educ., Curitiba, v. 9, n. 28, p. 587-604, set./ dez. 2009 
violências nas escolas diz respeito à responsabilidade do professor como ser social e histórico, portador de subjetividade, com um papel concreto no desenvolvimento e educação de crianças, jovens e adultos. D iz respeito à ação educativa, na qual estão embutidas responsabilidades políticas, sociais, pedagógicas, éticas, psicológicas, estéticas e científicas, que acontece pela mediação da palavra, da linguagem e postura dos (as) professores (as) principalmente em sala de aula (K OEHLER, 2003).

V ejamos a clareza e simplicidade com que Rúdio (1983, p. 52) nos mostra o professor em ação exercendo sua profissão na sala de aula:

[...] quando entra na sala de aula, o professor pode estar apenas interessado em ensinar, transmitir conhecimentos e informações, esclarecer sobre assuntos de sua matéria. Mas existe outro ensinamento que ele comunica quer queira ou não: a lição de si mesmo como pessoa humana. Isso significa que, quando vai dar aula, mais do que a notícia de sua matéria, ele está inevitavelmente se anunciando a seus alunos, quer deseje ou não, pelo seu modo de falar, de agir, embutidos na entonação de voz, na maneira de gesticular, no modo como trata seus alunos, na forma de encarar suas obrigações profissionais, nos comentários que faz sobre 0 mundo, as pessoas, nas opiniões sobre valores como felicidade, amor, religião, etc... E é justamente aí, que de maneira mais profunda se torna educador.

Nossa postura exige mudança de cultura e de representações, mas não sejamos ingênuos quanto às dificuldades específicas quanto à violência sobre o homossexual e o sentimento homofóbico. Como já posto, historicamente a heterossexualidade é a norma. (Re)conhecer, historicamente, a identidade de gênero enquanto parte das profundas mudanças na sociedade é reconhecer a existência da homofobia e compreender a existência de tipos diferentes de família na sociedade como conseqüência das relações sociais que se refletem na própria escola. Portanto, o professor precisa ver-se enquanto um protagonista fundamental nas relações da E scola, enquanto sujeito capaz de intervir e transformar.

A ssim entendemos que o trabalho educativo do professor não pode conter, em seu bojo, o rancor, a rispidez, o mau humor, 0 desrespeito, a ofensa, o cinismo, o autoritarismo que humilha e envergonha. Contribuir com uma cultura de paz é ensinar a condição humana individual e coletiva.

Rev. Diálogo Educ., Curitiba, v. 9, n. 28, p. 587-604, set./ dez. 2009 
A representação social da homofobia na cidade de Lorena/ SP

603

\section{REFERÊNCIAS}

ABRAMOVAY, M.; CASTRO, M. G.; SILVA, L. B. da. Juventudes e sexualidade. Brasília: Unesco, 2004.

BABBIE, E. Métodos de pesquisa survey. Belo Horizonte: Ed. da UFMG, 1999.

BARD IN, L. Análise de conteúdo. Lisboa: Edições 70, 1977.

BRASIL. Ministério da Saúde. Conselho Nacional de Combate à D iscriminação. Brasil sem homofobia: Programa de combate à violência e à discriminação contra G LTB e promoção da cidadania homossexual. Brasília: Ministério da Saúde, 2004.

FO UCAULT, M. H istónia da sexualidade I: a vontade de saber. Rio de Janeiro: Graal, 1999.

GIDD ENS, A. A transformação da intimidade: sexualidade, amor e erotismo na sociedade moderna. São Paulo: Paulista, 1993.

JUNQUEIRA, R. O reconhecimento da diversidade sexual e a problematização da homofobia no contexto escolar. In: SEMINÁRIO: CORPO, GÊNERO E SEXUALIDADE: DISCUTINDO PRÁTICAS EDUCATIVAS, 3., 2007. Rio Grande. Anais... Rio G rande, RS: FURG, 2007. p. 60-63.

JO D ELET, D. Les representation sociales: um domaine em expansion. In: Les representations socials. 2éd. Paris: PUF, 1991.

KOEHLER, S. M. F. Violência psicológica: um estudo do fenômeno na relação professor aluno. 2003. 210 f. Tese (D outorado Psicologia do Escolar e Desenvolvimento Humano) - Instituto de Psicologia da Universidade de São Paulo. São Paulo, 2003.

MO TT, L. Homo-afetividade e direitos humanos. Rev. Estud. Fem., Florianópolis, v. 14, n. 2, p. 509-521, 2006. Disponível em: <www.scielo.br/ pdf/ ref/ v14n2/ a11v14n2.pdf>. Acesso em: 29 jun. 2009.

MO SCOVICI, S. A representação social da psicanálise. Rio de Janeiro: Zahar, 1978.

RAMIRE S NETO, L. H abitus de gênero e experiência escolar: jovens gays no ensino médio em São Paulo. 2006. 170 f. Dissertação (Mestrado em Educação) Faculdade de Educação, Universidade de São Paulo, São Paulo, 2006.

Rev. Diálogo Educ., Curitiba, v. 9, n. 28, p. 587-604, set./ dez. 2009 
RUDIO, F. V. Em busca de uma educação para a fraternidade. São Paulo: D om Bosco, 1983.

SMIGAY, K. E. Sexismo, homofobia e outras expressões correlatas de violência: desafios para a psicologia política. Psicologia em Revista, Belo Horizonte, v. 8, n. 11, p. 32-46, 2002.

VIANNA, C.; RIDENTI, S. U. Relações de gênero na escola: diferenças e preconceitos. In: AQUINO, J. G. Diferenças e preconceito na escola: alternativas teóricas e práticas. São Paulo: Summus, 1998. p. 93-105.

Recebido: 25/ 01/ 2009

Received: 01/ 25/ 2009

Aprovado: 02/ 04/ 2009

A pproved: 04/ 02/ 2009

Revisado: 17/ 09/ 2009

Reviewed: 09/ 17/ 2009

Rev. Diálogo Educ., Curitiba, v. 9, n. 28, p. 587-604, set./ dez. 2009 